\title{
Agricultura biológica na Região Centro de Portugal: sub-região da Beira Litoral e no Vale do Lis
}

\author{
Organic agriculture in the center region of Portugal: case study in the \\ sub-region of Beira Litoral and in the Lis Valley
}

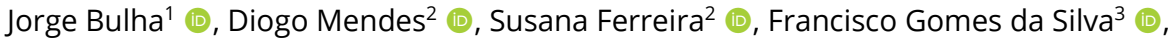 \\ Maria de Fátima Oliveira ${ }^{4}$ (1) \\ 1Direção Regional de Agricultura e Pescas do Centro, Coimbra, Portugal. E-mail: jorge.bulha@drapc.gov.pt \\ ${ }^{2}$ Instituto Politécnico de Coimbra, Escola Superior Agrária, Coimbra, Portugal. E-mail: diogoptd@gmail.com; \\ susana.ferreira@esac.pt \\ ${ }^{3}$ Instituto Superior de Agronomia, Universidade de Lisboa, Lisboa, Portugal. E-mail: fgsilva@isa.ulisboa.pt \\ ${ }^{4}$ Instituto Politécnico de Coimbra, Escola Superior Agrária, Centro de Recursos Naturais, Ambiente e Sociedade (CERNAS), \\ Coimbra, Portugal. E-mail: foliveira@esac.pt
}

Como citar: Bulha, J., Mendes, D., Ferreira, S., Silva, F. G., \& Oliveira, M. F. (2021). Agricultura biológica na Região Centro de Portugal: sub-região da Beira Litoral e no Vale do Lis. Revista de Economia e Sociologia Rural, 59(1), e238880. https://doi.org/10.1590/1806-9479.2021.238880

Resumo: A agricultura biológica cria um mercado para bens e serviços ambientais, e os produtores podem ser recompensados pela sua gestão agroambiental através de preços premium e pela Política Agrícola Comum (PAC). O objetivo deste trabalho foi caracterizar os agricultores da Região Centro de agricultura do ponto de vista socioeconómico, além de avaliar a propensão para a mudança do modo produtivo para a agricultura biológica e identificar as principais dificuldades para a mudança. Foi realizado o estudo dos efeitos das políticas agrícolas na evolução da agricultura biológica. Foram realizados estudos através de entrevistas presenciais resultando em dois estudos de caso. Os estudos de caso apresentam metodologias distintas, mas complementares. O trabalho revelou que a PAC contribuiu para o desenvolvimento deste setor e os dados alcançados permitem aos investigadores desenvolver técnicas para que os agricultores possam superar os obstáculos e aumentar a competitividade da cadeia de valor. A renovação geracional e o aumento da dimensão da exploração são factores a considerar para o progresso da agricultura biológica. É necessário gerar formação adequada às necessidades e fornecer informações precisas e reais sobre as dificuldades e benefícios desse modo de agricultura.

Palavras-chave: agricultura biológica, beira litoral, propensão à mudança.

\begin{abstract}
Organic farming creates a market for environmental goods and services, and farmers can be rewarded for their agri-environment management through premium prices and the Common Agricultural Policy (CAP). The objective of this work was to characterize the farmers of the Center Region from the socioeconomic point of view and to evaluate the willingness to change the productive mode for organic farming and to identify the main difficulties for change. The study of the effects of agricultural policies on the evolution of organic farming was carried out. Studies were conducted through face-toface interviews resulting in two case studies. The case studies present different but complementary methodologies. The work revealed that CAP has contributed to the development of this sector and the data obtained allow researchers to develop techniques for farmers to overcome obstacles and increase the competitiveness of the value chain. Generational renewal and increased farm size are factors to consider for the progress of organic farming. It is necessary to generate training appropriate to the needs, to provide accurate and real information about the difficulties and benefits of this mode of agriculture.
\end{abstract}

Keywords: organic farming, beira litoral, willingness to change. 


\section{INTRODUÇÃO}

O movimento da agricultura biológica na Europa surgiu no início do século XX como resultado de um conjunto de ideias, crenças e filosofias. A agricultura em Modo de Produção Biológica (MPB) cria um mercado para bens e serviços ambientais, e os produtores podem ser recompensados pela sua gestão agroambiental através de preços premium do produto (McBride et al., 2005) e pela Política Agrícola Comum (PAC).

Da análise realizada por regiões, a América do Norte registou o mais elevado valor de vendas de produtos em Modo de Produção Biológica, avaliados em 43,0 bilhões de euros, seguida pela Europa (37,3 bilhões de euros) e pela Ásia (9,6 bilhões de euros). A tendência de crescimento não é apenas observada na América do Norte e na América do Sul, sendo também observada na Oceânia e na África. Em Portugal, o mercado de produtos biológicos apresentou, em 2011 o valor de 21 milhões de euros (International Federation of Organic Agriculture Movements, 2019). A Oceânia é a região que detinha, em 2017, cerca de $51 \%$ da área mundial em MPB e que apresenta a maior percentagem de agricultura em MPB, com $8,6 \%$ da sua área agrícola, seguida pela União Europeia (UE), que, em 2017, representava cerca de $21 \%$ da área mundial em MPB, sendo que cerca de 7,2\% da sua área agrícola estava em MPB (FiBL Statistics, 2019; International Federation of Organic Agriculture Movements, 2019).

A UE apresentou, em 2014, o Plano de Ação para a produção em MPB a fim de garantir o crescimento sustentado da oferta e da procura, mantendo a confiança do consumidor, definindo três prioridades: 1) aumento da competitividade dos produtores em MPB; 2) aumentar e consolidar a confiança dos consumidores na agricultura e nos alimentos em MPB, assim como a confiança nos produtos biológicos importados, e por último 3) reforçar a dimensão externa do sistema de produção em MPB da UE (EU Commission, 2014).

A agricultura em MPB apresentou uma Taxa Crescimento Anual (TCA) entre 2000-2002 e 2015-2017 (média trienal) de 6\% ao ano em área, de 5\% em número de agricultores e de 6\% em relação a todos os operadores (processadores, importadores e exportadores) em MPB.

Uma variável importante que as estatísticas europeias revelam é que a dimensão média de Superfície Agrícola Útil (SAU) numa exploração não biológica era em 2013 de 16 hectares (ha), enquanto numa exploração totalmente em MPB na UE foi de 41 ha.

A força de trabalho por exploração não biológica (convencional ou integrada) foi de 0,9 Unidades de Trabalho Ano (UTA) e de 1,5 UTA para as explorações agrícolas inteiramente em MPB (Eurostat, 2019). Argumenta-se frequentemente que a agricultura em MPB emprega mais trabalho do que a agricultura convencional porque é mais intensiva em mão de obra do que a agricultura não biológica. Os dados da EC (EU Commission, 2016) mostraram que este facto não se verifica para a maioria dos Estados-Membros, mas estes resultados têm de ser observados com cuidado, porque a intensidade da mão de obra também depende da orientação do produto. Os resultados expõem a capacidade da agricultura em MPB de se desenvolver, nomeadamente se consideramos que a dimensão da exploração é um factor importante para que o agricultor possa investir em tecnologia e aproveitar as economias de escala.

\subsection{Agricultura Biológica na União Europeia}

O apoio da UE foi importante para a conversão e será crucial para que as áreas ainda em conversão sejam convertidas em agricultura biológica. Este apoio é também importante não só em termos financeiros, mas também em termos de formação dos agricultores. Para uma análise mais detalhada, seria necessário conhecer o efeito das políticas agrícolas nos novos países e tentar diferenciar este efeito da situação em termos de área agrícola e produtividade no período anterior à sua entrada na UE, atentando para o efeito da abertura de mercado.

A Figura 1 apresenta a taxa de conversão das áreas sob conversão para a agricultura em MPB em totalmente convertida. É de salientar os elevados valores da taxa de conversão dos novos países da UE em relação aos países da UE-13. Nesta relação, é de salientar a situação dos novos países antes da entrada destes na UE. Os apoios e as áreas com cultivos pouco diferenciados e a entrada num novo mercado poderão ter sido a alavanca para estes países, enquanto os países das UE-13 já tinham as áreas e formas de cultivo definidas 
A produção de produtos em MPB provém de áreas totalmente convertidas e a percentagem da área sob conversão no total da área em MPB convertida e em conversão será um indicador do potencial de crescimento.

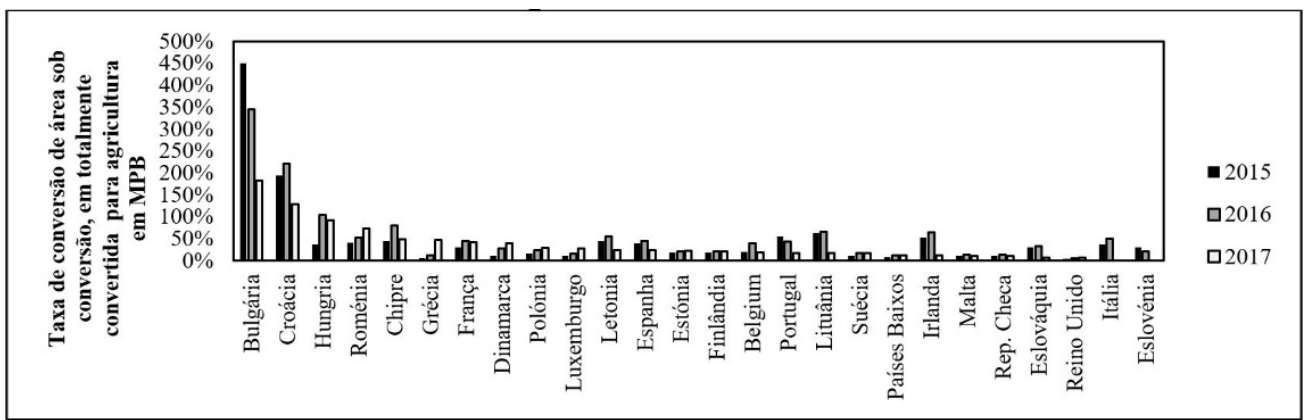

Figura 1 - Taxa de conversão de área sob conversão em totalmente convertida para agricultura em MPB. Fonte: Eurostat DataBase (FiBL Statistics, 2019).

Cerca de 12 países apresentaram uma taxa superior a 20\% e 15 países, uma taxa inferior a $20 \%$, tendo quatro países taxas inferior a $10 \%$ em conversão (Figura 2). Se considerarmos a UE, em 2016 e 2017, a taxa de área sob conversão em total convertida e sob conversão foi de $28 \%$ e $23 \%$, respectivamente. Se consideramos a relação entre a área em conversão em totalmente convertida na UE, esse valor representava, em 2017, cerca de 39\%.

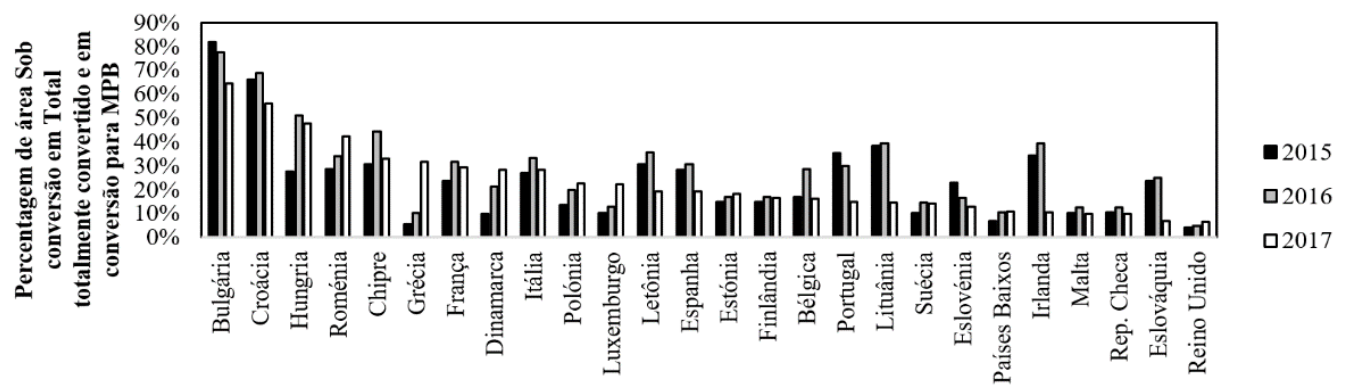

Figura 2 - Percentagem de área em conversão em total convertida e sob conversão. Fonte: Eurostat DataBase (FiBL Statistics, 2019).

Os movimentos de conversão apresentam alguma instabilidade e a leitura dos dados requer cuidado. Existem alguns agricultores que iniciam o processo para a conversão nas não o terminam. Os novos países da UE são aqueles que apresentam valores mais elevados e permitem averiguar o potencial de crescimento da agricultura em MPB.

O Eurostat (2019) revela que as culturas mais relevantes na agricultura biológica são as pastagens permanentes, que representam 58\% da área em MPB, seguidas dos cereais (20\%) e das culturas permanentes (15\%).

\section{Objetivo e Metodologia}

O objetivo deste trabalho foi a caracterização socioeconômica dos agricultores em MPB da Região Centro, bem como avaliar a propensão para a mudança. O trabalho apresenta dois estudos de caso na Beira Litoral (BL). Para atingir os objetivos, foi definida uma metodologia em duas fases. Numa primeira fase, foi realizada a análise de dados recolhidos através de entrevistas pessoais, aplicando um guia de entrevista a ser aplicado em campo aos produtores em MPB na BL, e na segunda fase, foram realizadas entrevistas aos produtores no Vale do Lis para avaliar a sua propensão para a mudança para o MPB, com amostra estratificada.

A metodologia foi construída considerando diferentes formas de investigação, porque uma abordagem poderia configurar-se não completa se utilizar um só método de análise (Bell, 
2005). Com estas duas fases, procurou-se avaliar as dificuldades sentidas pelo agricultor tanto para a conversão como para manutenção das explorações em MPB.

Na primeira fase, foram analisadas 245 explorações registadas na Direção Regional de Agricultura e Pescas do Centro (DRAPC), na Beira Litoral em MPB, correspondendo à área de 2.404 ha. Foi realizado, com todos os produtores registados, um contacto telefónico para validação dos elementos de contacto disponíveis, verificação da manutenção de atividade agrícola e para proposta e agendamento de entrevista, de acordo com o guião (Anexo 1), na exploração ou em local mais prático para ambas as partes. As entrevistas decorreram em 2017.

$\mathrm{Na}$ escolha pelo guião de entrevista para a obtenção dos dados quantitativos e qualitativos, foram consideradas as vantagens e desvantagens de uma entrevista com guião em relação ao inquérito de perguntas fechadas e abertas. Com a entrevista com guião, tentou-se reduzir a rigidez do questionário e obter o máximo de informação que iria permitir formar uma base a ser utilizada a ser utilizada em outros trabalhos futuros (Schilling, 2003; Paiva, 2010).

Através desta primeira avaliação, apurou-se que só 222 explorações (221 produtores) mantinham a atividade agrícola na BL numa área de 1.342 ha, o que correspondeu a uma redução de $9,4 \%$ no número de explorações e de $44 \%$ da área. Dos 221 produtores em MPB da BL, foram contatados telefonicamente 137 produtores (62\% do número de produtores e $83,3 \%$ da área da $\mathrm{BL}$ ), o que corresponde a 1.124 ha. Foram realizadas 86 entrevistas na exploração ( $38 \%$ dos produtores e $69 \%$ da área em MPB, o que corresponde a 928 ha).

Para análise socioeconômica do produtor, só foram considerados as respostas dos produtores proprietários da exploração (76 entrevistas).

No Vale do Lis, foram realizadas entrevistas dirigidas à predisposição à mudança para Agricultura em MPB com todos os agricultores e não só com os agricultores em MPB. A área de estudo está integrada na área administrada pela Associação de Regantes e Beneficiários do Vale do Lis (ARBVL), que abrange cerca de 2.000 ha e apresenta uma elevada heterogeneidade em relação à dimensão das parcelas. As entrevistas tiveram o apoio do técnico da ARBVL, que facilitou o contato entre o entrevistador e o entrevistado. A entrevista era constituída por perguntas fechadas e abertas (Anexo 2 ), e foram consideradas as questões levantadas pela literatura (Norman et al., 1995).

O estudo abrangeu os proprietários e os agricultores das parcelas.

Realizou-se uma estratificação para se obter a amostra, segundo a Lei de Gauss. Resultaram três conjuntos de amostras representativas das várias classes de dimensão das explorações: 20 proprietários com maior área (> 8,5 ha), 20 proprietários com área de muito pequena dimensão (área $\leq 25 \mathrm{~m}^{2}$ ) e 21 proprietários com áreas entre 0,5 e 2 ha. Esta estratificação foi necessária porque são predominantes os proprietários de reduzida dimensão de área, mas são os proprietários das explorações de grande dimensão os que apresentam um maior volume de vendas e são os que têm uma maior participação e influência nas decisões do AHVL

Quando da realização das entrevistas, foi entregue uma brochura sobre a Estratégia Nacional para a Agricultura Biológica (Hagatong, 2018). As entrevistas decorreram nos meses de março e abril de 2019, tendo-se obtido um total de 57 entrevistas. Os casos de estudos da região Beira Litoral e o Vale do Lis estão inseridos na Região Centro de Portugal (Anexo 3).

Os dados recolhidos foram analisados através do software SPSS 25. Para medir a força da associação entre as variáveis, utilizou-se o coeficiente de correlação de Pearson ( $r$ ) e o coeficiente de correlação de Spearman (ró), que se aplica quando as variáveis não seguem uma distribuição normal. Existem diferenças de metodologia entre os dois estudos de casos, mas o objetivo é conhecer as dificuldades da agricultura em MPB, bem como a predisposição para este tipo de agricultura na Região Centro. 


\section{Resultados e Discussão}

\subsection{A agricultura em MPB em Portugal e na Região Centro}

Para melhor compreensão e enquadrar o trabalho de campo, foi realizada uma análise descritiva da evolução da agricultura em MPB em Portugal e na Região Centro.

Portugal teve vários programas do Programa de Desenvolvimento Rural (PDR), o PRODER (Programa de Desenvolvimento Rural, 2007-2013) através da Ação 2.2.1 (Alteração de modos de produção agrícola) e o PDR2020 (Programa de Desenvolvimento Rural 2014-2020) por meio da Ação 7.1 (Agricultura biológica), que ajudaram na evolução, em Portugal, da agricultura em MPB.

Este desenvolvimento permitiu que a área em MPB total correspondesse a 7\% do total da SAU portuguesa e representasse $2 \%$ do total da superfície agrícola em MPB da UE-28 em 2017, com uma taxa de crescimento entre 2012 e 2017 idêntica à UE (Anexo 4).

Desde de 2012 até 2017, a área convertida ou sob conversão em Portugal aumentou cerca de $26 \%$, crescimento superior à média EU, que foi de $25 \%$.

Em 2010, foi observada a maior área de agricultura em MPB apoiada pelo PRODER, com valores totais da ordem de 128 mil ha (Figura 3). A partir de 2010 a 2014, houve uma redução progressiva da área em MPB apoiada, atingindo um mínimo de aproximadamente 71 mil ha, em 2014 (Programa de Desenvolvimento Rural, 2019). A entrada em vigor do PDR2020 permitiu um aumento na área apoiada pela Operação (OP.) 7.1.1., Conversão para Agricultura Biológica, atingindo os 80 mil ha e, em conjunto com a OP. 7.1.2., Manutenção em Agricultura Biológica, área suportada pela Ação 7.1., foi de aproximadamente 226 mil ha, em 2017 (Programa de Desenvolvimento Rural, 2017).

Entre 2016-2017, a área apoiada para conversão para a produção em MPB foi invariavelmente menor do que as que receberam suporte de manutenção, ou seja, não houve um incremento de novas entradas em relação aos períodos anteriores, mas sim a transição da OP. 7.1.1. para a OP. 7.1.2., Manutenção em Agricultura Biológica (Figura 3). Em relação à Região Centro, observamos uma evolução semelhante a Portugal continental, com a diferença na OP. 7.1.1, em que existe um aumento das novas áreas para conversão.

A Figura 4 demonstra que, em 2011, o PRODER atribuiu um valor máximo de 15 milhões de euros (M€) à agricultura biológica em Portugal Continental, mas, entre 2011 e 2014, houve uma redução progressiva dos subsídios concedidos via PRODER.

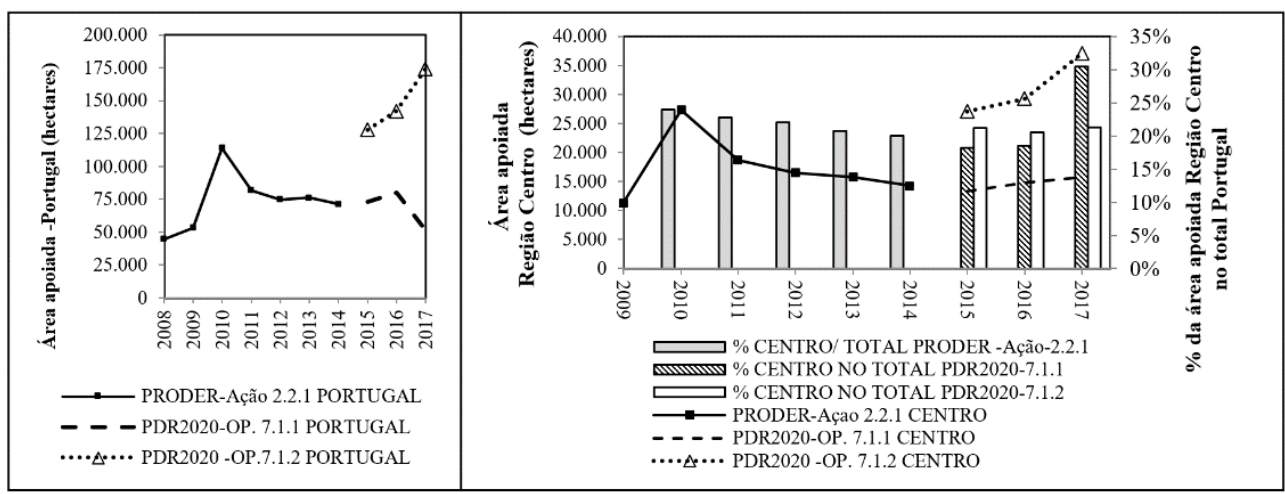

Figura 3 - Evolução da área (ha) em MPB apoiada em Portugal Continental e na Região Centro, por Ação e por Operação no PRODER e PDR2020 (hectares). Fonte: Adaptado dos Relatórios de Execução do PRODER (vários anos) e do PDR2020 (Programa de Desenvolvimento Rural, 2015, 2016, 2017).

O PDR2020 permitiu um aumento significativo na alocação da agricultura biológica para a conversão de $21 \mathrm{M} €$ em 2016. É de se salientar que na ação 2.2.1 não se separava a conversão da manutenção. No PDR2020, existe essa separação e, considerando os dois apoios, estes totalizaram cerca de 52 M€ em 2016. Em 2017, verifica-se uma redução do financiamento de ambas as operações (26 M€) 


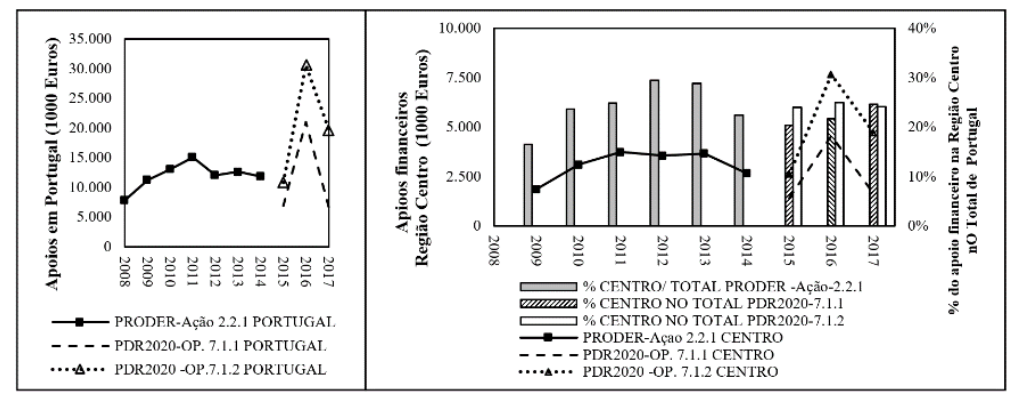

Figura 4 - Evolução dos apoios financeiros pelo PDR em Portugal Continental e na Região Centro, por Ação e por Operação no PRODER e PDR2020 (Mil Euros). Fonte: Adaptado dos Relatórios de Execução do PRODER (vários anos) e do PDR2020 (Programa de Desenvolvimento Rural, 2015, 2016, 2017).

Se consideramos a Região Centro, os apoios seguem a mesma tendência do total nacional, mas verifica-se que houve um aumento percentual da área apoiada que não foi acompanhada pelo aumento percentual do financiamento (Figura 3 e Figura 4)

De acordo com a Figura 5, houve um crescimento potencial da área e um crescimento linear do número de produtores em MPB. É importante salientar que a área média por exploração (ha/expl.) entre 1994 e 1998 (média quinquenal) foi de 39 ha/expl. e esse valor, entre 2013 e 2017, passou para $72 \mathrm{ha} / \mathrm{expl}$. Este valor é muito superior ao valor médio por exploração para a agricultura em Portugal Continental, que foi em 2016 de 14,9 ha/expl. (Instituto Nacional de Estatística, 2017).

O crescimento da área ente 1994 e 1998 e 2013 e 2017, foi de $1.781 \%$ e do número de produtores foi de $101 \%$, o que levou a um crescimento da área por exploração de $85 \%$.

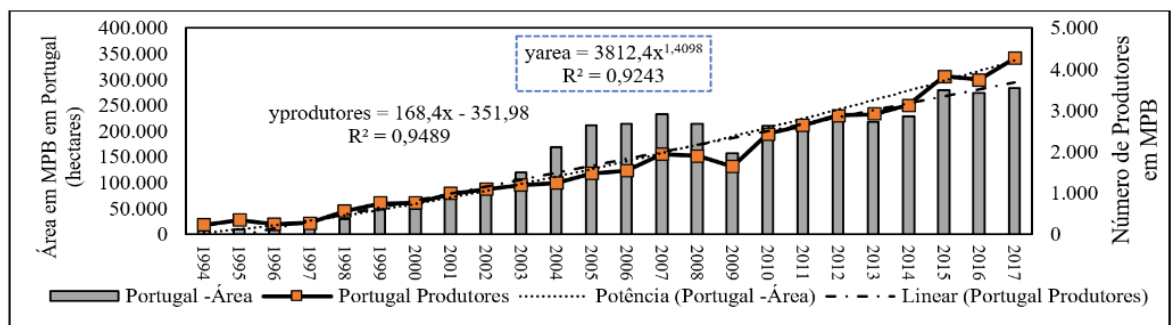

Figura 5 - Evolução da área e do número de produtores em Portugal Continental em MPB. Fonte: DGADR (Direção-Geral de Agricultura e Desenvolvimento Rural, 2019).

Entre 1994 e 1998, a Região Centro representava cerca de 20\% da área e 12\% dos produtores em MPB de Portugal Continental, mas entre 2013 e 2017, esse valor foi 19\% da área e $25 \%$ do número de produtores. Houve um aumento do número de produtores em relação ao total nacional e uma redução da representatividade da área por aumento das áreas de outras regiões. No entanto, é de salientar a importância da Região Centro no desenvolvimento deste modo de produção. São evidentes as diferenças entre as duas subregiões, a Beira Litoral (BL) e a Beira Interior (BI), entre 1994 e 2017, no que se refere às áreas e ao número de produtores de agricultura em MPB (produções vegetais) (Figura 6).

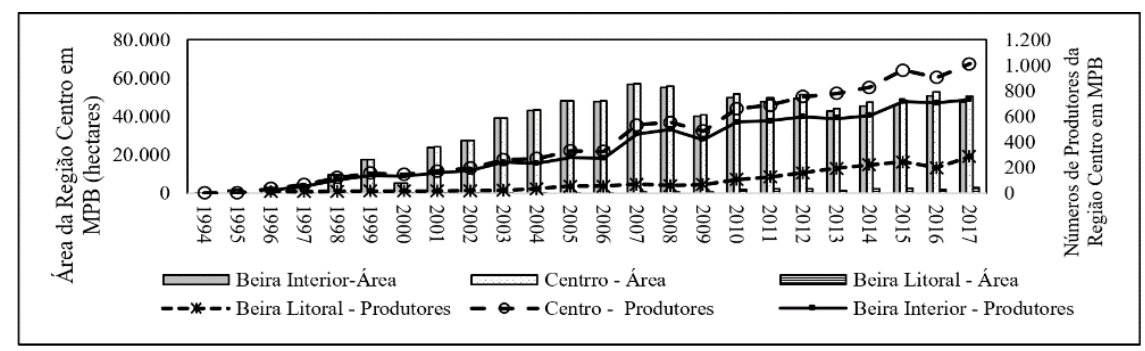

Figura 6 - Área e número de produtores de agricultura em MPB na Região Centro. Fonte: DGADR (Direção-Geral de Agricultura e Desenvolvimento Rural, 2019). 
A região da BL contribuiu entre 2013 e 2017 com 4\% (média quinquenal) para a área da Região Centro, mas representou 25\% dos produtores. A BI, entre 2013 e 2017, representou $96 \%$ da área e $75 \%$ do número de explorações da Região Centro. Na Região Centro, a área média foi entre 2013 e 2017 de 55 ha/expl. (BL: 9 ha/expl.; Bl: 70 ha/expl.) (Direção-Geral de Agricultura e Desenvolvimento Rural, 2019).

As distribuições das áreas apoiadas por tipo de culturas mantêm-se semelhantes tanto no PRODER como para o PDR2020. As pastagens permanentes e as pastagens permanentes biodiversas representaram cerca $60 \%$ do total da área apoiada pelo PDR.

Em 2017, os prados e pastagens permanentes representaram 61\%, as outras culturas temporárias, 22\%, e o olival e frutos secos, cerca de 13\% da área apoiada pelo PDR2020 pela OP 7.1.1. Pela OP. 7.1.2., a distribuição é semelhante (67\% prados e pastagens permanentes e $17 \%$ outras culturas temporárias).

Em nível de Portugal, entre 2008 e 2017, as pastagens representaram cerca de $67 \%$ das culturas em MPB, seguidas das culturas forrageiras (9\%), com um aumento desta cultura em termos relativos e absoluto (crescimento de 128\% entre 2011 e 2017), seguida do olival com 9\% e com crescimento de 16\%, entre 2011 e 2017 . É relevante a importância das pastagens, o que justifica as áreas das explorações em MPB serem superiores à média nacional (Figura 7).

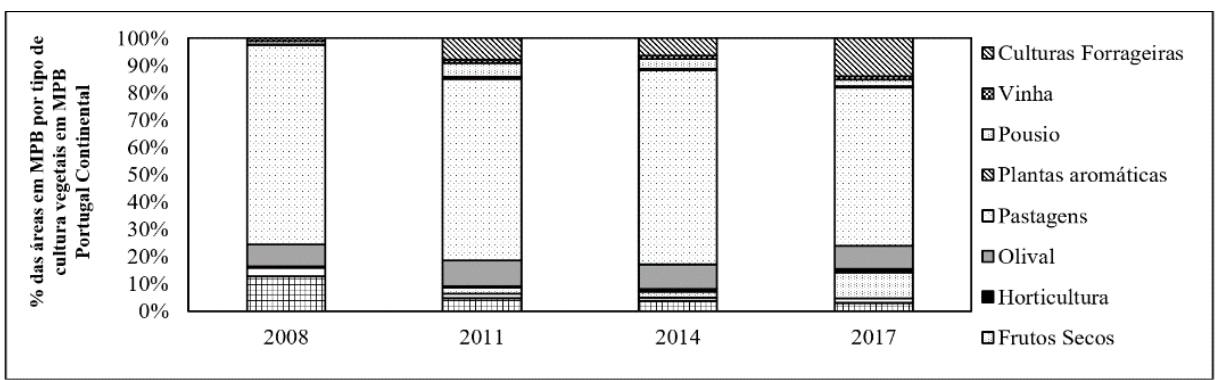

Figura 7 - Percentagem das culturas vegetais no total das culturas vegetais no MPB Portugal. Fonte: DGADR (Direção-Geral de Agricultura e Desenvolvimento Rural, 2019).

A distribuição das culturas em Portugal Continental e na Região Centro é semelhante (Figura 8).

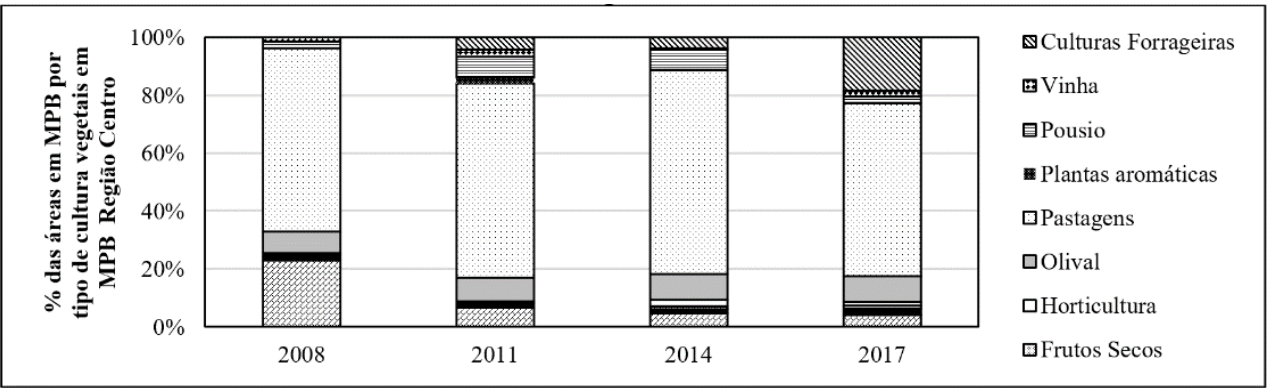

Figura 8 - Percentagem das culturas vegetais no total das culturas vegetais no MPB na Região Centro. Fonte: DGADR (Direção-Geral de Agricultura e Desenvolvimento Rural, 2019).

Nas sub-regiões, observa-se uma diferença em termos de área e na distribuição das culturas. A sub-região BL representava, em 2017, cerca de $51 \%$ da área cultivada na Região Centro com plantas aromáticas (Figura 8). A sub-região Bl, registou um decréscimo de $16 \%$ na área cultivada total em MPB e a BL, um crescimento de $331 \%$, o que está relacionado ao facto de que, em 2008, a BI representava 99\% da área em MPB da Região Centro, e em 2017, esse valor passou para 95\%, ou seja, na BI não houve um aumento de novas áreas em MPB.

A Região Centro abrange uma área de $28.462 \mathrm{~km}^{2}$ e representa 16,1\% (585.904 ha) da SAU de Portugal Continental. A Região Centro possui 87.044 explorações (33\% das explorações portuguesas) com uma área por exploração de 6,7 ha/expl., inferior à média 
nacional (14,1 ha/expl.), sendo de salientar, entre 2013 e 2016, um crescimento de 0,9\% do número de explorações, de $5 \%$ da SAU e de $4,1 \%$ da área por exploração. Em nível nacional, no mesmo período, houve um decréscimo do número de explorações $(-2,1 \%)$, uma manutenção da SAU e um crescimento da área por exploração de 2,1\% (Instituto Nacional de Estatística, 2017).

Através da base de dados da DRAPC, foi realizada uma caracterização da agricultura em MPB da região. Do total de 977 produtores registados na base de dados DRAPC, 77\% encontram-se na BI. Estes valores são ligeiramente distintos dos valores da Direção Geral de Agricultura e Desenvolvimento Rural (DGADR), que cita um total de 1.367 produtores (vegetais e produção animal) representando a $\mathrm{Bl}$, cerca de $95 \%$ do número de produtores. A área média das explorações em MPB na base da DRAPC foi 50,13 ha/expl., um pouco inferior aos dados da DGADR (66,3 ha/expl., 2017).

Na base da DRAPC, a área média da exploração em MPB na BL foi de aproximadamente 6 ha/expl., substancialmente inferior à área média da Bl, que é 63,9 ha/expl., e 75\% das explorações na BL apresentam uma área até os 4,1 ha/expl. Na Bl, 75\% das explorações têm até $66,7 \mathrm{ha} / \mathrm{expl}$.

De acordo com a Tabela 1, o número de produtores em MPB que se dedica exclusivamente à produção pecuária é de $2,7 \%$. Cerca de $62,3 \%$ dedicam-se à produção agrícola (vegetal). A maioria das explorações agrícolas possui entre dois e três tipos de distintas Orientação Técnico-Econômica (OTE) (Tabela 1).

Tabela 1 - Número de explorações em MPB, percentagem por atividade no total e OTE por exploração na Região Centro, 2017.

\begin{tabular}{|c|c|c|c|c|c|c|c|c|c|c|c|}
\hline \multirow{3}{*}{ Regiōes } & \multicolumn{6}{|c|}{ Atividade (Explorações) } & \multirow{2}{*}{\multicolumn{2}{|c|}{ Total }} & \multicolumn{3}{|c|}{ OTE por exploração } \\
\hline & \multicolumn{2}{|c|}{ Agrícola } & \multicolumn{2}{|c|}{ Pecuária } & \multicolumn{2}{|c|}{ Agropecuária } & & & \multirow{2}{*}{ Média } & \multirow{2}{*}{ Mediana } & \multirow{2}{*}{ Máximo } \\
\hline & $\mathbf{N}^{0}$ & $\%$ & $\mathbf{N}^{\circ}$ & $\%$ & $\mathbf{N}^{\circ}$ & $\%$ & $\mathbf{N}^{\circ}$ & $\%$ & & & \\
\hline $\begin{array}{c}\text { Beira } \\
\text { Litoral }\end{array}$ & 200 & 87,3 & 7 & 3,1 & 22 & 10 & 229 & 23 & 1.87 & 1 & 7 \\
\hline $\begin{array}{c}\text { Beira } \\
\text { Interior }\end{array}$ & 409 & 54,7 & 19 & 2,5 & 320 & 43 & 748 & 77 & 2.36 & 2 & 8 \\
\hline Centro & 609 & 62,3 & 26 & 2,7 & 342 & 35 & 977 & 100 & 2.24 & 2 & 8 \\
\hline
\end{tabular}

Fonte: Elaborado com dados próprios da DRAPC (2017, não publicado).

As Pastagens ocupam 69,9\% da área na agricultura em MPB, seguidas pelo Olival $(8,9 \%)$ e pelas Culturas Forrageiras (5,1\%). Cerca de $10,2 \%$ da SAU da Região Centro está em agricultura em MPB, mas a maior parte da área situa-se na BI. A agricultura da BL representa, de acordo com a DGADR, cerca de 6\% da SAU da Região Centro e 1\% da SAU nacional em MPB. A BI representava em 2017 cerca de 94\% da SAU da Região Centro e 18\% da SAU em Portugal Continental em MPB.

Os produtores de produção animal representaram cerca de $27 \%$ dos produtores de Portugal Continental e cerca de $93 \%$ dos produtores da Região Centro, e $35 \%$ dos produtores da Refião Centro estão envolvidos na produção animal (Direção-Geral de Agricultura e Desenvolvimento Rural, 2019).

Os produtores com pecuária exploram, em média, uma única OTE pecuária, denotando especialização, sendo de salientar que, no que tange aos pequenos ruminantes (ovinos e caprinos), a BI representa 32\% do efetivo do Continente. Na Tabela 2, podemos observar a distribuição das culturas, por área, número de explorações e área por exploração em 2017, nas sub-regiões e na Região Centro. As pastagens ocupam a maior área nas duas regiões, 19\% na BL e $72 \%$ na BI. Na BL, é de salientar a importância das culturas forrageiras e da fruticultura. Como cada exploração poderá ter mais de um tipo de cultura, o número de explorações poderá dizer respeito a diferentes culturas. 
Tabela 2 - Culturas em MPB na Região Centro

\begin{tabular}{|c|c|c|c|c|c|c|c|c|c|c|c|c|}
\hline \multirow{3}{*}{$\begin{array}{l}\text { Culturas } \\
\text { Arvenses }\end{array}$} & \multicolumn{2}{|c|}{ BL } & \multicolumn{2}{|c|}{ BI } & \multicolumn{2}{|c|}{ Centro } & BL & BI & Centro & BL & BI & Centro \\
\hline & $\begin{array}{l}\text { Área } \\
\text { (ha) }\end{array}$ & $\%$ & $\begin{array}{l}\text { Área } \\
\text { (ha) }\end{array}$ & $\%$ & $\begin{array}{l}\text { Área } \\
\text { (ha) }\end{array}$ & $\%$ & \multicolumn{3}{|c|}{$\begin{array}{c}\mathbf{N}^{\mathrm{a}} \text { de explorações } \\
\left(\mathbf{N}^{0}\right)\end{array}$} & \multicolumn{3}{|c|}{$\begin{array}{l}\text { Área por exploração } \\
\text { (ha/expl.) }\end{array}$} \\
\hline & 96 & 7,2 & 1345 & 2,9 & 1441 & 3,1 & 13 & 96 & 109 & 7,4 & 14,0 & 13,2 \\
\hline Forrageiras & 286 & 21,4 & 2103 & 4,6 & 2389 & 5,1 & 7 & 73 & 80 & 40,9 & 28,8 & 29,9 \\
\hline Fruticultura & 205 & 15,3 & 1016 & 2,2 & 1220 & 2,6 & 142 & 203 & 345 & 1,4 & 5,0 & 3,5 \\
\hline Frutos secos & 67 & 5 & 422 & 0,9 & 489 & 1 & 22 & 104 & 126 & 3,0 & 4,1 & 3,9 \\
\hline Horticultura & 118 & 8,8 & 168 & 0,4 & 285 & 0,6 & 68 & 39 & 107 & 1,7 & 4,3 & 2,7 \\
\hline Olival & 37 & 2,7 & 4162 & 9,1 & 4198 & 8,9 & 28 & 409 & 437 & 1,3 & 10,2 & 9,6 \\
\hline Pastagens & 239 & 17,8 & 32792 & 71,5 & 33030 & 70 & 27 & 361 & 388 & 8,8 & 90,8 & 85,1 \\
\hline Aromáticas & 42 & 3,1 & 30 & 0,1 & 72 & 0,2 & 33 & 20 & 53 & 1,3 & 1,5 & 1,4 \\
\hline Pousio & 118 & 8,8 & 3057 & 6,7 & 3174 & 6,7 & 49 & 202 & 251 & 2,4 & 15,1 & 12,6 \\
\hline Vinha & 133 & 10 & 765 & 1,7 & 899 & 1,9 & 27 & 154 & 181 & 4,9 & 5,0 & 5,0 \\
\hline Total & 1339 & 100 & 45859 & 100 & 47198 & 100 & & & & & & \\
\hline
\end{tabular}

Fonte: Elaborado com dados próprios da DRAPC (2017, não publicado).

\subsection{Estudo de caso: Agricultores em MPB da Beira Litoral}

O estudo socioeconómico foi realizado com os produtores de agricultura em MPB na Beira Litoral, como foi mencionado na metodologia. As entrevistas foram dirigidas aos proprietários das explorações, sendo $65 \%$ dos entrevistados proprietários e $12 \%$ exploram as suas propriedades e são rendeiros. O comodato é uma figura importante na forma de exploração. O proprietário é geralmente o agricultor do sexo masculino $(72,37 \%)$ e, na maior parte dos casos (61,8\%), tem entre $30-49$ anos, e 35,5\% entre $40-49$ anos, sendo de salientar que 50\% dos agricultores têm ensino superior. Apenas 25\% dos agricultores apresentam formação na área agrícola, mas cerca de $64,5 \%$ dos agricultores realizaram formação agrícola de curta duração ( $<250$ horas) e de longa duração ( $>250$ horas).

Cerca de $55,3 \%$ dos produtores têm a agricultura como sua principal atividade. Estes dados são mais elevados dos que a média nacional, em que só 5,6\% têm formação superior e só $6,1 \%$ têm como rendimento exclusivo a agricultura, e $12,8 \%$ têm a agricultura como atividade principal (Instituto Nacional de Estatística, 2017). A motivação para se dedicarem à agricultura foi essencialmente a rentabilização da terra (64,5\%).

A experiência familiar na agricultura e o descontentamento profissional foram factores importantes para a decisão de entrar na agricultura e na agricultura biológica. Cerca das $61,8 \%$ das respostas dos entrevistados (era possível escolher mais de uma opção) indicaram que optaram pela agricultura em MPB por uma questão de filosofia de vida e por viabilidade econômica, que era dada pelo preço mais elevado no mercado em relação aos produtos produzidos em outros modos de cultivo. A importância dos subsídios para a agricultura biológica que superam os custos associados à certificação foi mencionada e alguns agricultores observaram uma tendência para o aumento da procura por produtos em MPB.

A versatilidade de os produtos em MPB poderem ser comercializados em outro modo de cultura foi referida por $22 \%$ dos entrevistados. A maioria dos agricultores financiou a atividade agrícola apenas com recursos próprios $(61,4 \%)$. Os produtores afirmam que o apoio técnico provém de competências agrícolas internas ou de consultoria e/ou da comercialização de produtos agrícolas e de associações de colegas. Em termos de vendas, cerca de $52 \%$ dos produtores vendem sua produção para grossistas e $34 \%$ vendem sua produção diretamente ao consumidor final, e $33 \%$ para o pequeno retalhista (circuito curto). Existem produtores que vendem em simultâneo para vários canais. No entanto, cerca de 33 produtores (40\%) vendem diretamente para a exportação. O preço de venda da produção é maioritariamente estabelecido pelo cliente $(50,6 \%)$. Um factor a ser observado é que $53 \%$ dos produtores fazem algum marketing/publicidade.

Alguns produtores pretenderam aumentar as áreas das explorações, mas é difícil encontrar terras para comprar ou para alugar. Os proprietários preferem, 
independentemente dos valores propostos para arrendamento ou compra de terra, manter as propriedades abandonadas. A existência do Banco de Terras não teve impacto na região.

Nas entrevistas, foram reveladas críticas quanto à insuficiência de iniciativas de formação obrigatória, tanto em termos de dispersão no território nacional como em termos de frequência de realização e publicidade. Questões e problemas relacionados com a qualidade da formação foram referidos, considerando que o conteúdo das formações é superficial e desajustado da realidade da agricultura em MPB. Foram apresentadas críticas aos organismos certificadores e à assessoria/consultoria agrícola, e realçam temas sobre a credibilidade da agricultura em MPB.

Os agricultores consideraram que as entidades certificadoras/consultadoria se recorrem do desconhecimento de alguns produtores para interpretações abusivas do regulamento que rege a agricultura biológica, apresentando como obrigatórias formações que são meramente aconselhadas.

Em relação à perceção do consumidor, foi mencionado que o consumidor de produtos em MPB valoriza a certificação, mas o público em geral não reconhece a diferença entre a agricultura em MPB e a agricultura de produção integrada. As várias designações existentes no mercado, como a "produção natural", a "produção tradicional" e outras, tendem a dificultar a distinção entre diferentes modos de agricultura e a gerar confusão e criar dúvidas aos consumidores. Este trabalho permitiu observar que os produtores, nomeadamente de pequenos frutos frescos e de produção de plantas aromáticas com o objetivo de adquirir escala, adquirem e exportam a produção de outras explorações. Este processo é realizado por produtores independentes, associações de produtores, joint ventures ou consórcio.

\subsection{Estudo de caso: Caraterização do agricultor do Vale do Lis: Predisposição para a mudança para MPB}

Nesta seção, vamos analisar o trabalho efetuado no Vale do Lis através de uma entrevista que tinha como objetivos: caraterização sociodemográfica dos agricultores; conhecer a relevância e a motivação para a atividade agrícola; a titularidade da exploração e das parcelas; a orientação produtiva e o mercado; o modo de produção, e a predisposição de mudança para o MPB e os apoios necessários para a mudança.

Cerca de $75,5 \%$ dos entrevistados do Vale do Lis pertencem à faixa etária superior a 50 anos e $35,1 \%$ têm mais de 65 anos, sendo que $84,2 \%$ são do género masculino. O nível de escolaridade é inferior ao do estudo de caso anterior e poderá estar relacionado com o facto de que, neste estudo, os entrevistados foram os agricultores e proprietários que produzem de todos os modos de cultivos, diversamennte do estudo de caso anterior, no qual foram só entrevistados os produtores em MPB. Em relação às habilitações académica, 54,4\% só frequentaram até a $4^{a}$ classe, o que está associado à elevada faixa etária dos inquiridos. Os resultados do Vale dos Lis são inferiores aos obtidos no Inquérito à Estrutura das Explorações Agrícolas (Instituto Nacional de Estatística, 2017).

No entanto, se acompanharmos o Recenseamento Agrícola de 2009, os valores obtidos estão de acordo com a caracterização do produtor agrícola: "[...] produtor agrícola tipo é homem, tem 63 anos e apenas completou o primeiro ciclo do ensino básico [...]" (Instituto Nacional de Estatística, 2011, p. 3). A atividade agrícola tem um papel secundário para 57,9\% dos inquiridos. Os rendimentos obtidos permitem acrescentar um rendimento extra ao que auferem com a atividade principal porque arrendam as suas parcelas ou têm outra atividade em outro setor de atividade econômica.

Este facto confirma a importância da agricultura familiar em Portugal e o autoconsumo da estrutura agrícola (Portugal, 2018). Verifica-se uma correlação positiva fraca (5\% de nível de significância) entre a relevância da atividade agrícola e a classificação da dimensão das explorações $(r=0,301$; ró $=0,328)$. À medida que a dimensão das explorações vai diminuindo, a atividade agrícola vai perdendo relevância enquanto atividade principal e passa para um plano secundário.

A maioria dos proprietários cultiva as próprias parcelas $(78,2 \%)$, mas também há quem as arrende (12,7\%). O comodato é uma forma de exploração com relevância. Os proprietários que arrendam pretendem continuar a arrendar ou ceder e não vender. As respostas dos 
proprietários explicam a dificuldade que os arrendatários sentem em aceder à terra por completo e, consequentemente, a dificuldade de investimento de longo prazo.

A motivação para a prática da agricultura está relacionada com a rentabilização das terras (43\% das respostas) e com o facto de esta ser uma atividade familiar (30\% das respostas), tendo o proprietário a possibilidade de continuar um negócio que já existia na família.

Em relação ao destino da produção, verifica-se que não há uma resposta que predomine em relação às outras, na medida em que cerca de $44 \%$ dos entrevistados vendem toda a produção e $33 \%$ dos entrevistados só cultivam para autoconsumo. No entanto, correlacionando o destino da produção com a dimensão das explorações, existe uma correlação positiva fraca, com $5 \%$ de nível de significância, entre estas duas variáveis $(r=0,282 ;$ ró $=0,314)$. Exploração de menor dimensão implica maior autoconsumo.

Existe também uma correlação significativa ( $5 \%$ de significância) positiva média ( $r=0,433$ e ró $=0,432$ ) entre a idade e o destino da produção, o que significa que os agricultores de faixa etária mais elevada tendem a destinar-se à produção para o autoconsumo. Seria importante analisar num estudo futuro a relação específica dos canais de comercialização com o MPB. Em relação às OTE, é de salientar a importância das hortícolas (32\%), o milhogrão (28\%) e as pastagens e forragens (18\%).

Em relação ao modo de produção, apenas um agricultor produz em modo de produção biológico, os restantes indicaram que produzem em modo de produção integrada. A maior parte dos inquiridos (84\%) respondeu que não estava interessado em mudar o modo de produção para MPB, o que se verificou em todas as classes de dimensão das explorações. Tanto os proprietários que responderam que estavam interessados em mudar para MPB como os que não estavam interessados indicaram dois apoios fundamentais para a ajuda na conversão/mudança de decisão: a garantia de escoamento e os preços mais elevados de produção. Para tal, era necessária a diferenciação por parte do consumidor. No entanto, das 45 respostas obtidas, 32 foram no sentido de que não existem quaisquer apoios que os façam mudar de opinião.

Para estes proprietários, nenhum dos apoios elencados na entrevista funciona como alavanca para mudar para o MPB. Só dois referiram apoios que se incluem diretamente em incentivos do Estado: o apoio à comercialização e o apoio à conversão.

Existe uma correlação negativa significativa, em $5 \%$ de nível de significância, entre as habilitações acadêmicas e a predisposição a mudar $(r=-0,37$ e ró $=-0.34)$. Se relacionarmos com a idade, essa correlação é significativa em $1 \%$ de nível de significância $(r=-0,49$; ró $=-0,45)$. Quanto mais elevado for o nível de escolaridade e quanto mais jovem for o agricultor, maior é a predisposição para a mudança.

A análise dos dados da agricultura biológica na Região Centro teve importância no desenvolvimento da agricultura em MPB em nível nacional, mas apresenta diferenças significativas nas áreas de produção e na Orientação Técnico-Econômica.

Os estudos de caso revelaram que o agricultor em MPB na BL é na sua maioria do género masculino com idade compreendida entre 40 e 49 anos, tem a agricultura como atividade principal, é licenciado e a formação em agricultura foi obtida através de formações de curta e de longa duração. Os produtores são proprietários dos terrenos que exploram e financiam a atividade agrícola apenas com recurso de capitais próprios e escoam a sua produção para clientes nacionais, sendo que o preço de venda da produção é maioritariamente estabelecido pelo cliente.

Os agricultores no Vale do Lis são agricultores que se enquadram no contexto socioeconómico dos agricultores em nível nacional e o estudo de caso do Vale do Lis revelou que a estrutura da terra de pequena dimensão, o agricultor com baixo nível de escolaridade e de elevada taxa etária restringem o desenvolvimento da agricultura biológica.

Além disso, os agricultores enfrentam uma série de incertezas que explica a baixa adesão a esse modo de produção, a saber, o processo de certificação, o conhecimento técnico de novas tecnologias, especialmente a proteção de culturas, e os problemas de comercialização e garantia de rentabilidade.

Os resultados revelam que o factor idade, a propriedade da terra e a dimensão são factores importantes para o desenvolvimento da agricultura em MPB. É de se realçar que os 
preços dos produtos em MPB traduzem o reconhecimento dos consumidores de um produto diferenciado com a produção, implicando custos acrescidos, nomeadamente o acréscimo de mão de obra e a certificação que permite a diferenciação.

A caracterização socioeconômica nos dois estudos de caso pode ser importante para o desenvolvimento da agricultura em modo biológico, mas não explica as dificuldades de desenvolvimento deste modo de agricultura. Os agricultores em geral e os agricultores em MPB não são um grupo homogéneo e as suas escolhas dependem de opções pessoais, em termos tanto de valores como de questões de gestão da sua exploração.

Observa-se que a política permite apoiar a agricultura biológica, mas não é a variável da qual depende a escolha deste modo de agricultura. Darnhofer et al. (2005) referem que não se deve ocultar a complexidade das circunstâncias pelas quais os produtores entram na produção biológica e que entender melhor as atitudes e os motivos sobre os quais diferentes agricultores baseiam sua decisão e a heterogeneidade tem implicações na estratégia de promoção deste modo de produção e pode ajudar a modular medidas políticas para se adequar a essas estratégias.

As duas áreas apresentam diferenças na forma de comercialização, mas o circuito curto é uma questão a desenvolver em ambos os casos. Os circuitos curtos de comercialização em ambos os casos foram referidos como importantes, sendo de salientar a sua importância no Vale do Lis. Mastronardi et al. (2015) apresentam uma análise bibliográfica sobre a relação entre os circuitos curtos e a sustentabilidade da agricultura, e referem que os sistemas curtos promovem sistemas produtivos mais sustentáveis, tanto do ponto vista social como ambiental. Apesar do impacto positivo que os circuitos curtos podem ter no ambiente, segundo alguns autores, este pode não ser o factor fundamental para reduzir os efeitos negativos relacionados com o transporte, e eles argumentam que o efeito do circuito curto na sustentabilidade ambiental advém essencialmente do modo de agricultura com que estes circuitos geralmente estão inter-relacionados (Dimitri \& Greene, 2002). EPRSLibrary (2019) e Kneafsey et al. (2013) salientam o impacto dos circuitos curtos na UE em termos de sustentabilidade econômica, social e ambiental.

A valorização e a diferenciação pelo preço por parte do consumidor é elemento alavanca para o desenvolvimento deste modo de produção. Os agricultores convertidos e os não convertidos apresentam conhecimento adequado dos benefícios deste modo de produção e a necessidade de uma agricultura mais ecológica para a sustentabilidade econômica das explorações.

É manifesto o papel do Estado na promoção da agricultura em modo biológico, através da clarificação dos vários sistemas de produção e também do modo de comercialização, mas o maior contributo para o desenvolvimento da Agricultura em MPB resulta da procura, que tem valorizado o produto em termos de preço e do escoamento. $O$ aumento das parcelas e 0 esclarecimento sobre custos de produção, a mecanização da agricultura, o apoio aos jovens agricultores e a renovação geracional são questões importantes e serão factores a ter em consideração no desenvolvimento de políticas para este modo de agricultura. Realça-se ainda a grande receptividade em aprofundar conhecimentos para fundamentar tomadas de decisão, através de ações de divulgação ou na participação em ações do tipo demonstrativo.

Kuo \& Peters (2017) mencionam que o desenvolvimento da agricultura em MPB foi moldado por interações entre factores sociais, políticos e econômicos, e que o desenvolvimento da agricultura biológica é associado a um movimento econômico por meio da incorporação social, caracterizado por conhecimento, inovação e confiança; consequentemente, a literatura associa a escolha deste modo de produção com atributos sociais. Apesar de existir uma vasta bibliografia a interligar a agricultura em MPB com atributos sociais e ambientais (Lamine \& Bellon, 2009), o trabalho de Kuo \& Peters (2017) apresenta resultados controversos e salienta que agricultura não trabalha fora do sistema econômico e salienta o efeito de proximidade ou de vizinhança no desenvolvimento deste modo de produção e a necessidade de dimensão não só física das explorações mas também das organizações. Neste trabalho, é possível observar as interações entre os factores sociais e a necessidade de interação com a economia e os atributos sociais. Mas o desenvolvimento da agricultura biológica é diferente entre os Estados Membros da UE, em nível nacional, e como foi observado neste trabalho, em nível regional. Moschitz \& Stolze (2007) realçam estas 
diferenças em nível da Europa e destacam que o desenvolvimento da agricultura em MPB é limitado pelos atores políticos que operam na agricultura e pela falta de recursos das organizações em agricultura biológica. No entanto, essas limitações poderão ser ultrapassadas através da procura de parcerias políticas.

O financiamento pela PAC de acordo com os resultados obtidos não é o constrangimento mais significativo, pois outras políticas, como a formação e o acesso à terra são factores necessários para incrementar este modo de produção. Rozman et al. (2012) referem que os subsídios não são a única força motriz no sistema e mais importantes são as outras atividades que promovem a agricultura biológica

É importante observar que o trabalho demonstra que os agricultores e os potenciais agricultores em MPB não são um homogéneo e que os valores pessoais e as características sociodemográficas desempenham um papel importante nas suas opções. Meike et al. (2017) realçam essas diferenças nas tomadas de decisão do agricultor. Ressalta-se a importância dos atributos sociais e ambientais na opção por esse modo de agricultura, destacando-se a necessidade de incorporação no sistema produtivo e de mercado.

\section{Conclusão}

Existem várias maneiras de desenvolver uma agricultura ecologicamente correta. Os agricultores reconhecem o MPB como um factor positivo para o desenvolvimento de uma agricultura mais sustentável, mas apresentam um conjunto de questões que dificultam a sua implantação.

Os dois estudos de caso na Região Centro permitiram caracterizar o agricultor em MPB e avaliar a sua predisposição para a mudança, possibilitando obter uma fotografia mais próxima das estruturas agrícolas em MPB e em outros modos de produção. Permitem observar as caraterísticas socioeconômicas e as razões pela escolha por este modo de agricultura e os constrangimentos sentidos para a evolução da exploração, assim como possibilita observar os constrangimentos para essa escolha. Os resultados obtidos apontam para diversas dificuldades na conversão dos modos produtivos e na manutenção dos que já estão neste modo de produção.

O trabalho revelou elementos que permitem aos investigadores e instituições agrícolas ajudar os agricultores a superarem os obstáculos que enfrentam para a conversão em MPB, a sua manutenção, bem como incrementar a competitividade das explorações em MPB, fortalecendo os atores da cadeia de valor. O aumento da confiança na agricultura em MPB deverá ter a participação ativa dos agricultores, através de informação credível, certificação e transparente.

A confiança na agricultura biológica também depende da confiança dos agricultores. É necessário trabalhar para criar a formação adequada às suas necessidades, fornecendo informações precisas e reais sobre as dificuldades e os benefícios desse modo de agricultura. No entanto, os agricultores e os potenciais agricultores em MPB não são um grupo homogéneo e as diferenças têm de ter em consideração as escolhas, que dependem de valores pessoais e têm ver com as formas de gestão.

As políticas de Desenvolvimento Rural permitiram o desenvolvimento deste modo de agricultura, mas é importante ressaltar que são necessárias outras estratégias, sem esquecer que, para o produtor, o mercado é o motor do sistema produtivo.

Este trabalho deverá ser alargado em nível nacional, não somente para a caracterização dos agricultores em MPB mas também para aferir a predisposição à mudança em nível nacional, de forma a adequar os instrumentos públicos às necessidades do agricultor e para o desenvolvimento das cadeias agroalimentares.

\section{Bibliografia}

Bell, J. (2005), Doing your research project: a guide for first-time researchers in Education and Social Science (4th ed.). London: Open University Press.

Darnhofer, I., Schneeberger, W., \& Freyer, B. (2005). Converting or not converting to organic farming in Austria: farmer types and their rationale. Agriculture and Human Values, 22, 39-52. 
Dimitri, C., \& Greene, C. (2002), Recent Growth Patterns in the U.S. Organic Foods Market. U.S. Department of Agriculture, Economic Research Service, Market and Trade Economics Division and Resource Economics Division. Agriculture Information Bulletin, 777, 1-39.

Direção-Geral de Agricultura e Desenvolvimento Rural - DGADR. (2019). Portugal continental: produtores agrícolas (1994-2017). Lisboa: DGADR. Recuperado em 21 de maio de 2019, de https://www.dgadr.gov.pt/sustentavel/modo-de-producao-biologico

EPRSLibrary. (2019). Local agriculture and short food supply chains. Recuperado em 20 de maio de 2019, Recuperado em 21 de maio de 2019, de https://epthinktank.eu/2013/10/14/local-agriculture-andshort-food-supply-chains/

EU Commission. (2014). Action plan for the future of organic production in the European Union. Union European: EU Commission.

EU Commission. (2016). Facts and figures on organic agriculture in the European Union. Union European: DG Agriculture and Rural Development/EU Commission.

Eurostat. (2019). Eurostat statistics explained: organic farming statistics 2019. Recuperado em 5 de abril de 2019, de https://ec.europa.eu/eurostat/web/agriculture/data/database

FiBL Statistics (2019). FiBL Statistics - Key indicators on organic agriculture worldwide. Recuperado em 20 de maio de 2019, from https://statistics.fibl.org/world/key-indicators-world.html.

Hagatong, C. (2018). Estratégia Nacional para a Agricultura Biológica. In Anais do Seminário Agricultura Biológica: da Sustentabilidade à Competitividade. Samora Correia, Portugal. Recuperado em 12 de maio de 2019, de https://epthinktank.eu/2013/10/14/local-agriculture-and-short-food-supplychains/

Instituto Nacional de Estatística - INE. (2011). Recenseamento agrícola 2009 (pp. 36-37). Portugual: INE.

Instituto Nacional de Estatística - INE. (2017). Inquérito à estrutura das explorações agrícolas 2016. Portugual: INE.

International Federation of Organic Agriculture Movements - IFOAM. (2019). The World of Organic Agriculture 2019. Germany: IFOAM. Recuperado em 15 de maio de 2019, de https://www.ifoam.bio/en/news/2019/02/13/world-organic-agriculture-2019

Kneafsey, M., Venn, L., Schmutz, U., Balázs, B., Trenchard, L., Eyden-Wood, T., Bos, E., Foster, G. \& Blackett, M. (2013). Short food supply chains and local food systems in the EU. A state of play of their socio-economic characteristics (EUR - Scientific and Technical Research Reports). European Union: European Commission.

Kuo, H.-J., \& Peters, D. (2017). The socioeconomic geography of organic agriculture in the United States. Agroecology and Sustainable Food Systems, 41(9-10), 1162-1184.

Lamine, C., \& Bellon, S. (2009). Conversion to organic farming: a multidimensional research object at the crossroads of agricultural and social sciences. A review. Agronomy for Sustainable Development, $29,97-112$

Mastronardi, L., Marino, D., Cavallo, A., \& Giannelli, A. (2015). Exploring the role of farmers in short food supply chains: the case of Italy. The International Food and Agribusiness Management Review, 18(2), 109-130.

McBride, W., Grenne, C., Foreman, L. \& Ali, M. (2005). The profit potential of certified organic field crop production (No. ERR-188, Economic Research Report, 52 p.). Washington: USDA.

Meike W., Zasada, I Franke, C., Piorr, A., Raggi, M. \& Viaggi, D. (2017). Analysing behavioural differences of farm households: an example of income diversification strategies based on European farm survey data. Land Use Policy, 62, 172-184

Moschitz, H., \& Stolze, M. (2007). Policy networks of organic farming in Europe (Vol. 12, Organic Farming in Europe: Economics and Policy). Stuttgart: Universität Hohenheim.

Norman, D., Worman, F., Siebert, J., \& Modiakgotla, E. (1995). The farming systems approach to development and appropriate technology generation. Rome: FAO. Recuperado em 27 de julho de 2013, de http://www.fao.org/3/v5330e/V5330e00.htm\#Contents

Paiva, A. (2010). Cooperativismo e Agricultura Biológica: estratégias de desenvolvimento sustentável para os prodyutores de leite da Cooperativa Agrícola de Leite [Tese de mestrado]. Lisboa: Instituto Português de Administração de Marketing.

Portugal. (2018, agosto 7). Decreto-Lei n. ${ }^{\circ}$ 64/2018. Consagra o estatuto da Agricultura Familiar. Diário da República, Lisboa. No. 151, Série 1.

Programa de Desenvolvimento Rural - ProDeR. (2015). Relatório de Execução Anual-2014/2015. Portugual: ProDeR. Recuperado em 15 de maio de 2019, de http://www.pdr-2020.pt/site 
Programa de Desenvolvimento Rural - ProDeR. (2016). Relatório de Execução Anual-2016. Portugual: ProDeR. Recuperado em 15 de maio de 2019, de http://www.pdr-2020.pt/site

Programa de Desenvolvimento Rural - ProDeR. (2017). Relatório de Execução Anual-2017. Portugual: ProDeR. Recuperado em 15 de maio de 2019, de http://www.pdr-2020.pt/site

Programa de Desenvolvimento Rural - ProDeR. (2019). Relatório de execução. Portugual: ProDeR. Recuperado em 10 de janeiro de 2019, de http://www.proder.pt/homepage.html

Rozman, Č., Pazek, K., Prišenk, J., Škraba, A., \& Kljajić, M. (2012). System dynamics model for policy scenarios of organic farming development. Organizacija, 45(5), 2012.

Schilling, N. (2003). Surveys and interviews. In R. J. Podesva \& R. D. Sharma (Eds.), Research methods in linguistics (Chap. 6). Cambridge: Cambridge University Press.

Submetido em: 18/Out/2019

Aceito em: 19/Maio/2020

Classificação JEL: Q18. 


\section{Anexo 1 - Guião de entrevista de campo}

1. Informação pessoal e profissional: Idade: Habilitações profissionais: Situação Profissional anterior: Razões da escolha pela agricultura e pela agricultura biológica.

2. Criação de empresa: Registo da empresa: Parcelário: Registo como agricultor: Certificação: Elaboração de projeto: Financiamento (Capitais Próprios: Créditos Bancários: Subsídios e Incentivos): Implementação de projeto.

3. Atividade da empresa: Relação com fornecedores: Forma de exploração: Área de Produção (certificada e não certificada): Canais de distribuição: Como e quando foram criados: Natureza: Mão de obra: Produtos: Equipamentos e Edificado: Marketing e Publicidade: Sustentabilidade e perspectivas de futuro. 


\section{Anexo 2 - Inquérito aos agricultores do A.H. do Vale do Lis}

O presente inquérito, que pretende servir de apoio ao estudo dos modos de produção no AHVL, é anónimo e confidencial, e os dados recolhidos servem exclusivamente para ser tratados no âmbito do Grupo Operacional para a Gestão da Água do Vale do Lis. Obrigado pela sua colaboração.

1. Idade (assinalar com $X$ a resposta correta)

$\square<20$ anos

$\square$ 20-40 anos

$\square$ 41-49 anos

$\square$ 50-64 anos

$\square \geq 65$ anos

2. Género (assinalar com $X$ a resposta correta)

$\square$ Masculino

$\square$ Feminino

3. Habilitações literárias (assinalar com $X$ a resposta correta)

$\square$ Até a $4^{\mathrm{a}}$ classe

$\square$ Até o $9^{\circ}$ ano

$\square 12^{\circ}$ ano

$\square$ Bacharelado ou Licenciatura

$\checkmark$ Mestrado ou Doutoramento

4. Relevância da atividade agrícola (assinalar com X a resposta correta)

$\checkmark$ A agricultura é a minha principal atividade e fonte de rendimento.

$\checkmark$ A agricultura é a minha atividade secundária e apoia o rendimento familiar.

5. Motivação para a prática da atividade agrícola [assinalar com $\mathrm{X}$ a(s) resposta(s) correta(s)]. Indique as duas principais razões, caso haja mais que uma motivação.

$\square$ Foi sempre uma atividade familiar.

$\square$ Quero ser agricultor e tenho formação acadêmica na área agrícola.

$\square$ Estava desempregado(a).

$\square$ Quero ser agricultor e tenho terrenos que quero rentabilizar.

$\square$ Estava descontente profissionalmente e resolvi mudar de profissão, aproveitando os apoios do PDR.

$\square$ Estava descontente profissionalmente e resolvi mudar de vida.

6. Relativamente à propriedade das parcelas que cultiva no Vale do Lis (assinalar com X a resposta correta)

$\square$ Sou proprietário.

$\square$ Sou arrendatário ("rendeiro"). $\rightarrow$ O SEU INQUÉRITO TERMINOU.

$\square$ Exploro por comodato ("empréstimo gratuito"). $\rightarrow$ O SEU INQUÉRITO TERMINOU.

$\square$ Sou proprietário e arrendatário ("rendeiro").

๑ Sou proprietário e também exploro por comodato ("empréstimo gratuito").

7. Se respondeu que é proprietário (assinalar com $X$ a resposta correta)

$\square$ Sou eu que cultivo a(s) minha(s) parcela(s).

$\square$ Arrendo a(s) minha(s) parcela(s). $\rightarrow$ PASSE PARA A PERGUNTA 15

$\square$ Cultivo algumas parcelas e arrendo/cedo por comodato

$\square$ Cedo a(s) minha(s) parcela(s) por comodato ("empréstimo gratuito") $\rightarrow$ PASSE PARA A

PERGUNTA 15 
8. Destino da produção: (assinalar com $X$ a resposta correta)

$\square$ Vendo toda a produção.

$\square$ Vendo uma parte da produção e a outra parte é para consumo próprio.

$\square$ Produzo apenas para consumo próprio $\rightarrow$ PASSE PARA A PERGUNTA 12

9. Indique, por ordem de importância, para que canais vende: (escrever $1^{\circ}, 2^{\circ}, 3^{\circ}, 4^{\circ}$, por ordem de importância do volume de vendas)

$\square$ Vendo diretamente ao consumidor final (mercado ou na empresa).

$\square$ Vendo a pequenos retalhistas.

$\square$ Vendo para a cooperativa ou para grossistas.

$\square$ Vendo a grandes superfícies.

10. Mercado (assinalar com $X$ a resposta correta)

$\square$ Vendo apenas para o mercado nacional.

$\checkmark$ Vendo apenas para o mercado estrangeiro.

$\checkmark$ Vendo para o mercado nacional e para o mercado estrangeiro.

11. Indique as quatro (4) principais produções nas suas parcelas: (escrever $1^{\circ}, 2^{\circ}, 3^{\circ}$ e $4^{\circ}$, por ordem de importância da área ocupada)

$\square$ Hortícolas

$\square$ Vinha

$\square$ Arroz

$\square$ Milho (grão)

$\square$ Pastagens e forragens

$\square$ Frutícolas

$\square$ Bacelos

$\square$ Pequenos frutos

$\square$ Outras Quais?

12. Modo de produção (assinalar com $X$ a resposta correta)

$\square$ Modo de produção biológico

$\square$ Modo de produção integrada

$\square$ Produção convencional

$\square$ Nenhuma das anteriores

13. Se respondeu que produz no modo de produção integrada e considerando que existe uma Estratégia Nacional para a Agricultura Biológica e um Plano de Ação para a produção e promoção de produtos biológicos, está disponível para mudar para o modo de produção biológico? Entregar doc. "Estratégia Nacional para a $A B^{\prime}$

Sim. Por quê?

Não. Por quê?

Se a resposta anterior for Sim, diga quais os apoios que considera mais necessários para ajudar na reconversão.

Se a resposta for Não, diga quais os apoios que precisava ter para mudar de opinião (indique três respostas por ordem de importância).

$\begin{array}{ccc}\text { Apoios } & \begin{array}{c}\text { Se a resposta tiver } \\ \text { sido SIM }\end{array} & \begin{array}{c}\text { Se a resposta tiver sido } \\ \text { NÃO }\end{array} \\ \text { Apoio na comercialização } & \\ \text { Subsídio para reconversão } & \\ \text { Apoio nos custos dos factores de produção } \\ \text { (fertilizantes e meios de proteção das culturas } \\ \text { contra pragas e infestantes) }\end{array}$




$\begin{array}{ccc}\text { Apoios } & \begin{array}{c}\text { Se a resposta tiver } \\ \text { sido SIM }\end{array} & \begin{array}{c}\text { Se a resposta tiver sido } \\ \text { NÃo }\end{array} \\ \text { Formação Técnica } & \\ \text { Apoio financeiro para a certificação } \\ \text { Garantia de escoamento } \\ \text { Preços mais elevados da produção } \\ \text { Maior área de produção } \\ \text { Outros }\end{array}$

14. Uma vez que arrenda as suas parcelas ou as cede por comodato, qual o modo de exploração que prevê futuramente para as mesmas? (assinalar com $\mathrm{X}$ a resposta correta) $\square$ Pretendo continuar a arrendar/ceder.

$\square$ Pretendo começar a cultivá-las.

$\square$ Pretendo vendê-las. 
a)

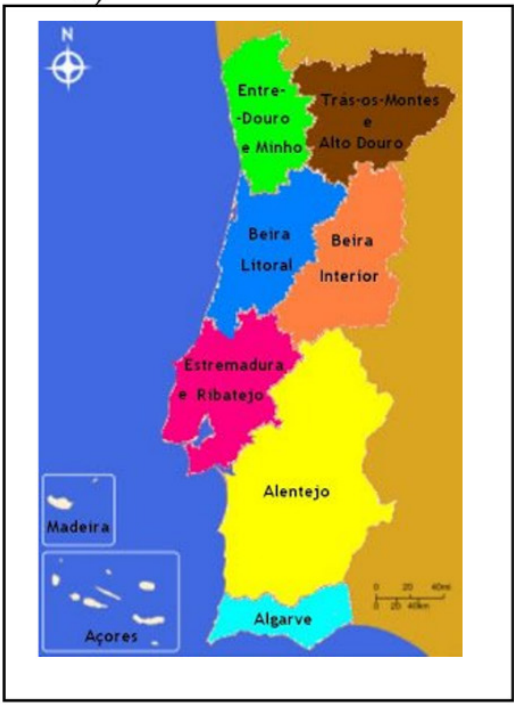

b)

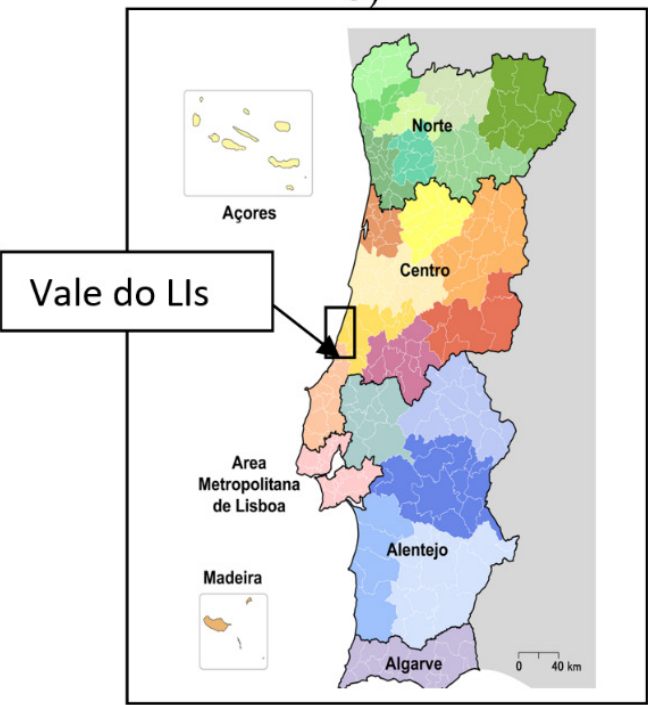

Fonte: https://pt.wikipedia.org/wiki/NUTS_de_Portugal

Anexo 4 - Percentagem do total da área totalmente convertido e em conversão para MPB e área agrícola total utilizada e total da área em MPB (hectares) na UE

\begin{tabular}{|c|c|c|c|c|c|c|c|c|c|}
\hline \multicolumn{7}{|c|}{$\begin{array}{l}\text { Percentagem da área em MPB no Total da Superfície } \\
\text { Agrícola Útil }\end{array}$} & \multirow{2}{*}{\multicolumn{2}{|c|}{$\begin{array}{c}\text { Total de área em } \\
\text { MPB } \\
1000 \text { ha }\end{array}$}} & \multirow{3}{*}{$\begin{array}{c}\begin{array}{c}\text { Taxa de } \\
\text { crescimento }\end{array} \\
\% \\
2012-2017\end{array}$} \\
\hline \multirow{2}{*}{$\frac{\text { Países }}{\text { Anos }}$} & \multicolumn{6}{|c|}{$\%$} & & & \\
\hline & 2012 & 2013 & 2014 & 2015 & 2016 & 2017 & 2012 & 2017 & \\
\hline EU - 28 & 5,64 & 5,70 & 5,78 & 6,20 & 6,68 & 7,03 & 10048 & 12560 & $25 \%$ \\
\hline Bélgica & 4,48 & 4,67 & 5,00 & 5,17 & 5,80 & 6,28 & 60 & 84 & $40 \%$ \\
\hline Bulgária & 0,76 & 1,13 & 0,96 & 2,37 & 3,20 & 2,72 & 39 & 137 & $249 \%$ \\
\hline Rep. Checa & 13,29 & 13,47 & 13,44 & 13,68 & 14,00 & 14,09 & 469 & 496 & $6 \%$ \\
\hline Dinamarca & 7,31 & 6,44 & 6,25 & 6,33 & 7,81 & 8,60 & 195 & 226 & $16 \%$ \\
\hline Alemanha & 5,76 & 6,04 & 6,18 & 6,34 & 6,82 & 6,82 & 960 & 1138 & $19 \%$ \\
\hline Estónia & 14,86 & 15,65 & 15,96 & 15,68 & 18,02 & 19,60 & 142 & 196 & $38 \%$ \\
\hline Irlanda & 1,16 & 1,20 & 1,16 & 1,65 & 1,72 & 1,66 & 53 & 74 & $41 \%$ \\
\hline Grécia & 9,01 & 7,36 & 6,72 & 7,70 & 6,50 & 7,96 & 463 & 410 & $-11 \%$ \\
\hline Espanha & 7,49 & 6,85 & 7,26 & 8,24 & 8,48 & 8,73 & 1757 & 2082 & $19 \%$ \\
\hline França & 3,55 & 3,66 & 3,87 & 4,54 & 5,29 & 5,99 & 1031 & 1744 & $69 \%$ \\
\hline Croácia & 2,40 & 3,13 & 4,03 & 4,94 & 6,05 & 6,46 & 32 & 97 & $203 \%$ \\
\hline Itália & 9,30 & 10,60 & 10,91 & 11,79 & 13,99 & 14,86 & 1167 & 1909 & $63 \%$ \\
\hline Chipre & 3,38 & 4,03 & 3,63 & 3,72 & 4,94 & 4,57 & 4 & 6 & $43 \%$ \\
\hline Eslováquia & 10,63 & 9,89 & 10,86 & 12,29 & 13,42 & 13,92 & 196 & 269 & $37 \%$ \\
\hline Lituânia & 5,51 & 5,74 & 5,57 & 7,11 & 7,50 & 7,98 & 157 & 234 & $50 \%$ \\
\hline $\begin{array}{c}\text { Luxemburg } \\
0\end{array}$ & 3,14 & 3,39 & 3,43 & 3,21 & 3,47 & 4,15 & 4 & 5 & $32 \%$ \\
\hline Hungria & 2,45 & 2,45 & 2,34 & 2,43 & 3,48 & 3,73 & 131 & 200 & $53 \%$ \\
\hline Malta & 0,32 & 0,06 & 0,29 & 0,25 & 0,21 & 0,35 & 0 & 0 & $11 \%$ \\
\hline $\begin{array}{l}\text { Países } \\
\text { Baixos }\end{array}$ & 2,61 & 2,65 & 2,67 & 2,67 & 2,91 & 3,14 & 48 & 56 & $17 \%$ \\
\hline Áustria & 18,62 & 18,40 & 19,35 & 20,30 & 21,25 & 23,37 & 533 & 621 & $16 \%$ \\
\hline Polônia & 4,51 & 4,65 & 4,56 & 4,03 & 3,72 & 3,41 & 655 & 495 & $-24 \%$ \\
\hline
\end{tabular}


Agricultura biológica na Região Centro de Portugal: sub-região da Beira Litoral e no Vale do Lis

\begin{tabular}{|c|c|c|c|c|c|c|c|c|c|}
\hline \multicolumn{7}{|c|}{$\begin{array}{l}\text { Percentagem da área em MPB no Total da Superfície } \\
\text { Agrícola Útil }\end{array}$} & \multirow{2}{*}{\multicolumn{2}{|c|}{$\begin{array}{c}\text { Total de área em } \\
\text { MPB } \\
1000 \text { ha } \\
\end{array}$}} & \multirow{3}{*}{$\begin{array}{c}\begin{array}{c}\text { Taxa de } \\
\text { crescimento }\end{array} \\
\% \\
2012-2017\end{array}$} \\
\hline \multirow{2}{*}{$\begin{array}{l}\text { Países } \\
\text { Anos }\end{array}$} & \multicolumn{6}{|c|}{$\%$} & & & \\
\hline & 2012 & 2013 & 2014 & 2015 & 2016 & 2017 & 2012 & 2017 & \\
\hline Portugal & 5,48 & 5,31 & 5,74 & 6,52 & 6,75 & 7,04 & 201 & 254 & $26 \%$ \\
\hline Roménia & 2,10 & 2,06 & 2,09 & 1,77 & 1,67 & 1,93 & 288 & 258 & $-10 \%$ \\
\hline Eslovénia & 7,32 & 8,07 & 8,55 & 8,85 & 9,12 & 9,60 & 35 & 46 & $32 \%$ \\
\hline Eslováquia & 8,53 & 8,18 & 9,37 & 9,47 & 9,75 & 9,90 & 164 & 189 & $15 \%$ \\
\hline Finlândia & 8,65 & 9,07 & 9,29 & 9,91 & 10,47 & 11,38 & 198 & 259 & $31 \%$ \\
\hline Suécia & 15,76 & 16,50 & 16,53 & 17,14 & 18,30 & 19,16 & 478 & 577 & $21 \%$ \\
\hline $\begin{array}{l}\text { Reino } \\
\text { Unido }\end{array}$ & 3,41 & 3,24 & 3,02 & 2,89 & 2,82 & 2,87 & 590 & 498 & $-16 \%$ \\
\hline
\end{tabular}

Fonte: Eurostat DataBase (consultado em 15/05/2019). 